\title{
PENGARUH MODEL PEMBELAJARAN COOPERATIVE BERKIRIM SALAM DAN SOAL TERHADAP HASIL BELAJAR PKN SISWA KELAS VII SMP NEGERI 20 PONTIANAK
}

\author{
Luvy Monica ${ }^{1}$, Erna Octavia ${ }^{2}$ \\ ${ }^{1,2}$ Program Studi PPKN Fakultas Ilmu Pendidikan dan Pengetahuan Sosial IKIP PGRI Pontianak \\ Jl. Ampera Nomor 88 Pontianak-78116, Telepon (0561) 748219 Fax. (0561) 6589855 \\ email: Luvymonica.1m@gmail.com
}

\begin{abstract}
Abstrak
Penelitian ini, bertujuan untuk mengetahui pengaruh model pembelajaran cooperative berkirim salam dan soal terhadap hasil belajar pendidikan kewarganegaraan siswa kelas VII di sekolah menengah pertama negeri 20 pontianak.Metode penelitian ini metode Kuantitatif jenis eksperimen. Berdasarkan hasil pengolahandata, maka dapat disimpulkan hasil penelitian ini sesuai dengan rumusan masalah sebagai berikut: (1) Hasil belajar siswa pada mata pelajaran Pendidikan Kewarganegaraan sebelum dilaksanakannya model pembelajaran cooperative berkirim salam dan soal terhadap hasil belajar pendidikan kewarganegaraan siswa kelas VII di Sekolah Menengah Pertama Negerti 20 Pontianak, termasuk dalam kategori "tidak tuntas", karena rata-rata hasil beajar yang dilakukan oleh peneliti adalah 60,94. (2) Hasil belajar siswa pada mata pelajaran Pendidikan Kewarganegaraan setelah dilaksanakannya model pembelajaran cooperative berkirim salam dan soal terhadap hasil belajar pendidikan kewarganegaraan siswa kelas VII di Sekolah Menengah Pertama Negerti 20 Pontianak.termasuk dalam kategori "Tuntas", karena rata-rata hasil belajar yang dilakukan oleh peneliti adalah 75,31. Ini dapat dilihat dari adanya keinginan siswa untuk berhasl dalam belajar, serta adanya semangat dan kebutuhan untuk meningkatkan hasil belajar dengan sangat baik.(3) Terdapat pengaruh model pembelajaran cooperative berkirim salam dan soal terhadap hasil belajar pendidikan kewarganegaraan siswa kelas VII di Sekolah Menengah Pertama Negerti 20 Pontianak. Ini dilihat dari perhitungan berapa besar pengaruh atau (tinggi rendah) menggunakan Effect Size yang hasilnya yaitu Es = 1.49 "tergolong tinggi" dengan Kriteria besarnya Effect Size adalah Es $<0,3$ tergolong rendah, 0,3 $\leq$ Es $\leq 0,7$ tergolong sedang, Es > 0,7 tergolong tinggi.
\end{abstract}

Kata Kunci: Cooperative berkirim salam dan soal, Hasil belajar siswa

\begin{abstract}
This study aims to determine the effect of cooperative learning models of sending greetings and questions to the learning outcomes of citizenship education in grade VII students at 20 Pontianak state junior high schools. The method of this research is quantitative method of experimental type. Based on the results of data processing, it can be concluded that the results of this study are in accordance with the formulation of the problem as follows: (1) Student learning outcomes in Civics Education subjects before implementing cooperative learning models sending greetings and questions on learning outcomes for citizenship education in Grade VII students in Negative Junior High School 20 Pontianak, included in the category of "incomplete", because the average study results conducted by researchers is 60.94. (2) Student learning outcomes in Citizenship Education subjects after the implementation of the cooperative learning model sending greetings and questions on the learning outcomes of citizenship education in Grade VII students of the 20th Middle School in Pontianak. Included in the category of "Completion", because the average learning outcomes are conducted by researchers is 75.31. This can be seen from the desire of students to succeed in learning, as well as the enthusiasm and the need to improve learning outcomes very well. (3) There is an influence of the cooperative learning model of sending greetings and questions to the learning outcomes of the eighth grade citizenship education at Negative Junior High School 20 Pontianak. This is seen from the calculation of how much influence or (high low) using the Effect Size, the result of which is ES $=1.49$ "classified as high" with the criteria for the size of Effect Size is ES $<0.3$ classified as low, $0.3 \leq E s \leq$ 0.7 classified as moderate, ES>0.7 is high.
\end{abstract}

Keywords: Cooperative sending greetings and questions, Student learning outcom

\section{PENDAHULUAN}

Pada umumnya pendidikan di Indonesia bertujuan untuk meningkatkan kualitas hidup manusia yang secara teknis operasional dilakukan melalui suatu proses pembelajaran. UU. 
Sisdikanas Nomor 20 Tahun 2003 menyebutkan bahwa: "pendidikan adalah usaha sadar dan terencana untuk mewujudkan suasana belajar dan proses pembelajaran agar peserta didik secara aktif mengembangkan potensi dirinya untuk memiliki kekuatan spiritual keagamaan, Pengendalian diri, kepribadan, kecerdasan, akhlak mulia, serta keterampilan yang diperlukan dirinya, bangsa dan negara".

Belajar pada dasarnya merupakan suatu proses mental karena orang belajar perlu memikir, menganalisis, mengingat dan mengambil kesimpulan dari apa yang dipelajari. Sehubungan dengan itu terdapat bermacam-macam pendapat tentang apa yang dimaksud dengan belajar (Zuldafrial 2010:05), belajar adalah proses yang dilakukan oleh manusia untuk mendapatkan aneka ragam competencis, skills, and attitude. Kemampuan (competence), keterampilan (skills), dan sikap (attitude) tersebut diperoleh secara bertahap dan berkelanjutan mulai dari masa bayi sampai masa tua melalui rangkaian proses belajar sepanjang hayat (Gredle dalam Winataputra 2001:05) masalah belajar mengajar adalah masalah yang sangat penting dan besar perannya dalam kehidupan manusia..Hal ini disebabkan oleh pentingnya proses pembelajaran dalam rangka meningkatkan kualitas pembelajaran seperti keterampilan sosial siswa. Dalam kerangka pembangunan SDM bangsa indonesia yang mampu menerima dalam pembelajaran dengan berbagai model diharapkan dapat memberikan pembaharuan pembelajaran.

Melalui model pembelajaran cooperative berkirim salam dan soal akan lebih mudah menemukan dan memahami pembelajaran - pembelajaran yang kurang menarik dan susah dipahami. Metode ini dikembangkan oleh Spencer Kagan dan kawan-kawan.Meskipun memiliki banyak kesamaan dengan metode lainnya, metode struktural menekankan pada struktur-struktur khusus yang dirancang untuk mempengaruhi pola-pola interaksi siswa.Berbagai struktur tersebut dikembangkan oleh Kagan dengan maksud menjadi alternatif dari berbagai struktur kelas yang lebih tradisional. Struktur-struktur Kagan menghendaki agar para siswa bekerja sama saling bergantung dalam kelompok-kelompok kecil secara cooperative. Salah satu metode struktural adalah berkirim salam dan soal (Sugiyanto, 2010: 43).

Teknik belajar mengajar berkirim salam dan soal memberi siswa kesempatan untuk melatih pengetahuan dan keterampilan mereka. Siswa membuat pertanyaan sendiri sehingga akan merasa lebih terdorong untuk belajar dan menjawab pertanyaan yang dibuat oleh temanteman sekelasnya. Kegiatan berkirim salam dan soal cocok untuk persiapan menjelang tes dan ujian. Teknik ini bisa digunakan dalam semua mata pelajaran dan untuk semua tingkatan usia didik (Sugiyanto, 2010).

Guru membagikan siswa dalam beberapa kelompok berempat-berempat, dan setiap kelompok ditugaskan untuk menulisakan beberapa pertanyaan yang akan dikirim ke kelompok 
lain. Guru bisa mengawasi dan membantu memilih soal-soal yang cocok, kemudian masingmasing kelompok mengirimkan satu orang utusan yang akan menyampaikan salam dan soal dari kelompoknya (salam kelompok yang bisa disertai sorak kelompok), setiap kelompok mengerjakan soal kiriman dari kelompok lain, setelah selesai, jawaban masing-masing kelompok di cocokan dengan jawaban kelompok yang membuat soal. Diakhir pembelajaran, guru dan siswa saling berefleksi mengenai apa yang telah dicapai dan dilakukan (Sugiyanto, 2010).

Dalam rangka meningkatkan kualitas pendidikan proses yang dilihat saat ini yaitu hasil belajar siswa. Baik buruknya hasil belajar akan berpengaruh pada kehidupan bangsa nantinya. Untuk meningkatkan hasil belajar, siswa juga harus mempunyai motivasi dan penggunaan model pembelajaran oleh guru model pembelajaran merupakan salah satu yang mempengaruhi hasil belajar siswa di SMP Negeri 20 Pontianak.

Hasil belajar adalah hasil atau prestasi yang diberikan kepada siswa dalam mengapresiasikan, sikap, nilai serta keterampilan siswa yang diberikan pada setiap akhir pembelajaran.Hasil pembelajaran merupakan kemampuan yang dimiliki oleh siswa. Nana Sudjana (2016: 22) mengatakan, "Hasil Belajar adalah kemampuan-kemampuan yang dimiliki siswa setelah ia menerima pengalaman belajarnya".Sedangkan menurut Zaenal Arifin (2010: 303) "Hasil belajar yang optimal dapat dilihat dari ketuntasan belajarnya, terampil dalam mengerjakan tugas, dan memiliki apresiasi yang baik terhadap pelajaran.” Menurut Asep Jihad dan Abdul Haris (2010:15) mengatakan, "Hasil belajar adalah perubahan tingkah laku siswa secara nyata setelah dilakukan proses belajar mengajar yang sesuai dengan tujuan pengajaran” .

Berdasarkan data yang didapatkan peneliti tanggal 29 April 2019 di kelas VII Sekolah Menengah Pertama Negeri 20 Pontianak, menunjukkan kenyataan bahwa hasil belajar siswa belum maksimal, hal ini tampak pada nilai ulangan harian siswa. Kemudian pada tanggal 24 Juli 2019 peneliti melihat hasil nilai ulangan harian siswa kelas VII yang masih dibawah rata-rata atau kurang maksimal yaitu 65,31 dan belum mencapai KKM 70,00 untuk mata pelajaran Pendidikan Pancasila dan Kewarganegaraan.

Rendahnya pencapaian nilai harian siswa ini menjadi indeks bahwa pembelajaran yang dilakukan belum efektif. KKM untuk mata pelajaran Pendidikan Pancasila dan Kewarganegraan di kelas VII Sekolah Mennegah Pertama Negeri 20 Pontianak adalah 70,00 (berdasarkan informasi dari Guru mata pelajaran Pendidikan Pancasila dan Kewarganegaran kelas VII). Salah satu penyebabnya adalah kurang semangat (motivasi) siswa dalam mengikuti proses pembelajaran., sehingga kondisi pembelajaran kurang aktif dan cenderung pasif terkadang komunikasi yang terjadi hanya bersifat satu arah antara guru dan siswa. Faktor penyebab 
tersebut adalah masalah yang harus diatasi terutama dalam upaya peningkatan hasil belajar siswa. Adapun sampel nilai dari salah satu kelas atau kelas VII C adalah sebagai berikut:

Tabel 1.1

Nilai Ulangan Harian Siswa

\begin{tabular}{ccc}
\hline No & Nilai Ulangan Harian & Jumlah siswa \\
\hline 1 & 50 & 5 orang \\
\hline 2 & 60 & 10 orang \\
\hline 3 & 70 & 13 orang \\
\hline 4 & 80 & 3 orang \\
\hline 5 & 90 & 1 orang \\
\hline \multicolumn{2}{r}{ Sumber Guru Mata Pelajaran PPKn Kelas VII }
\end{tabular}

Dari masalah diatas maka peneliti bermaksud melakukan penelitian tentang "Pengaruh Model Pembelajaran Cooperative Berkirim Salam dan Soal Terhadap Hasil Belajar Pendidikan Kewarganegaraan Siswa Kelas VII Di Sekolah Menengah Pertama Negeri 20 Pontianak.Harapan yang ingin dicapai dengan penelitian ini adalah dengan penerapan Model Pembelajaran Cooperative Berkirim Salam dan Soal Hasil Belajar Pendidikan Kewarganegaraan diharapkan memberikan pengaruh terhadap hasil belajar siswa yang selama ini masih belum optimal.Model Pembelajaran Cooperative Berkirim Salam dan Soal, dipilihnya dalam penelitian ini dimaksudkan agar model pembelajaran tersebut ada pengaruhnya serta dapat meningkatkan hasil belajar siswa.

\section{METODE}

Metode eksperimen adalah prosedur penelitian yang dilakukan untuk mengungkapkan hubungan sebab akibat dua variabel atau lebih, dengan mengendalikan pengaruh variabel yang lain (Nawawi, 2005:88). Suryabrata (2000:38) menyatakan bahwa penelitian eksperimen bertujuan untuk menyelidiki kemungkinan satu atau dua lebih kondisi perlakuan kepada satu atau lebih kelompok eksperimen Subana Sudrajat (2005:39) "Penelitian eksperimen adalah penelitian yang bertujuan melihat hubungan sebab-akibat". Digunakan metode eksperimen dalam penelitian ini, karena sesuai dengan tujuan penelitian yaitu untuk mengetahui seberapa besar pengaruh model pembelajaran Cooperative bentuk struktural (berkirim salam dan soal) terhadap hasil belajar siswa pada mata pelajaran pendidikan kewarganegaraan.

Rancangan yang digunakan dalam penelitian ini dengan pola One group pretest-postest design menurut Sugiyono (2011:83) rancangan ini digunakan satu kelompok subjek. Pertamatama dilakukan pengukuran, lalu dikenakan perlakuan untuk kalinya. Rancangan ini dapat di gambarkan sebagai berikut: 
Tabel 1.2

Desain Kelompok Tunggal dengan pretest-posttest

\begin{tabular}{ccc}
$\begin{array}{r}\text { Tes awal } \\
(\text { Pre-test })\end{array}$ & Perlakuan & $\begin{array}{r}\text { Tes akhir } \\
(\text { Post-test })\end{array}$ \\
\hline $\mathrm{O}_{1}$ & $\mathrm{X}_{1}$ & $\mathrm{O}_{2}$ \\
\hline
\end{tabular}

Populasi adalah keseluruhan atau totalitas dari objek penelitian menurut Hadari Nawawi (2005:141) bahwa "Populasi adalah seluruh objek penelitian yang dapat terdiri dari manusia, benda-benda, hewan, tumbuh-tumbuhan, gejala-gejala, nilai tes atau peristiwa sebagai sumber data yang memiliki karakteristik tertentu dalam suatu penelitian”. Sugiyono (2011:117) mengatakan bahwa "Populasi adalah wilayah generalisasi yang terdiri atas obyek atau subyek yang mempunyai kualitas dan karakteristik tertentu yang ditetapkan oleh peneliti untuk dipelajari dan kemudian ditarik kesimpulannya.

Berdasarkan pendapat diatas dapat disimpulkan bahwa populasi adalah keseluruhan dari objek yang dapat dijadikan sumber untuk memperoleh data dalam penelitian yang mempunyai karakteristik tertentu. Adapun yang menjadi populasi dalam penelitian ini adalah 1 orang guru mata pelajaran Pendidikan Kewarganegaraan dan siswa kelas VII C Sekolah Menengah Pertama Negeri 20 Pontianak dengan jumlah siswa sebanyak 32 orang. Dengan rincian dapat dilihat dalam tabel 3.2 sebagai berikut:

\section{Tabel 1.3}

\section{DISTRIBUSI POPULASI SISWA KELAS VII C SMP NEGERI 20 PONTIANAK}

\begin{tabular}{|c|c|c|c|c|}
\hline \multirow{2}{*}{ No } & \multirow{2}{*}{ Kelas } & \multicolumn{2}{|c|}{ Jenis Kelamin } & \multirow{2}{*}{$\begin{array}{l}\text { Jumlah } \\
\text { Siswa }\end{array}$} \\
\hline & & Laki-laki & Perempuan & \\
\hline 1 & VII & 17 & 15 & 32 \\
\hline \multicolumn{4}{|c|}{ Jumlah Siswa } & 32 \\
\hline
\end{tabular}

Sumber data: Tata Usaha SMP Negeri 20 Pontianak Tahun Ajaran 2019-2020.

Selanjutnya Sugiyono (2010:91) mengatakan bahwa: "Sampel adalah sebagian dari jumlah dan karakteristik yang dimiliki oleh populasi tersebut". Suharsimi Arikunto (2005: 11) sampel adalah sebagian atau wakil populasi yang diteliti. Sesuai dengan pengertian sampel secara umum, yaitu sebagian dari populasi suatu penelitian, maka peneliti mengikuti pendapat yang mengatakan sebagai berikut, "untuk sekedar ancer-ancer maka apabila subyeknya kurang dari 100 lebih baik diambil semua sehingga penelitannya merupakan penelitian populasi”. (Suharsimi Arikunto, 2005: 134). Berdasarkan pendapat diatas, dapat disimpulkan bahwa sampel merupakan bagian dari populasi yang akan menjadi sumber penelitian. 


\section{HASIL DAN PEMBAHASAN}

1. Hasil belajar siswa sebelum diterapkannya model pembelajaran cooperative berkirim salam dan soal.

Untuk menjawab sub masalah 1 dalam penelitian ini dengan menggunakan rumus ratarata (mean). Selanjutnya dalam menjawab sub masalah 1 maka diperoleh sebagaimana tertera pada Tabel 1.4:

Tabel 1.4

Hasil Belajar Siswa Pretest

\begin{tabular}{ccc}
\hline No & Nilai Pretest & Jumlah Siswa \\
\hline 1 & 50 & 11 orang \\
\hline 2 & 60 & 10 orang \\
\hline 3 & 70 & 8 orang \\
\hline 4 & 80 & 3 orang \\
\hline & Jumlah & 32 orang \\
\hline
\end{tabular}

Sumber Guru Mata Pelajaran PPKn Kelas VII

Berdasarkan tabel diatas yang didapat peneliti tentang hasil belajar siswa sebelum penerapan model pembelajaran cooperative berkirim salam dan soaldari 32 orang responden terdapat skor total minimal 1950, maka mean rata-rata hasil belajar siswa pada nilai pretest mata pelajaran Pendidikan Kewarganegaraan adalah sebagai berikut:

$$
\mathrm{M}=\frac{\sum \mathrm{X}}{\mathrm{N}}=\frac{1950}{32}=60,938
$$

Jika dibandingkan dengan tolak ukur maka masuk dalam kategori tidak tuntas.

2. Hasil belajar siswa sesudah diterapkannya model pembelajaran cooperative berkirim salam dan soal.

Untuk menjawab sub masalah 2 dalam penelitian ini dengan menggunakan rumus ratarata (mean). Selanjutnya dalam menjawab sub masalah 2 maka diperoleh sebagaimana tertera pada Tabel 1.5:

Tabel 1.5

Hasil Belajar Siswa Posttest

\begin{tabular}{ccc}
\hline No & Nilai Posttest & Jumlah Siswa \\
\hline 1 & 60 & 4 orang \\
\hline 2 & 70 & 12 orang \\
\hline 3 & 80 & 11 orang \\
\hline 4 & 90 & 5 orang \\
\hline & Jumlah & 32 orang \\
\hline
\end{tabular}

Sumber Guru Mata Pelajaran PPKn Kelas VII

Berdasarkan hasil belajar siswa setelah penerapan model pembelajaran cooperative berkirim salam dan soal dari 32 orang responden terdapat skor total minimal 2410, maka 
mean rata-rata hasil belajar siswa pada nilai posttest mata pelajaran Pendidikan Kewarganegaraan adalah sebagai berikut:

$$
\mathrm{M}=\frac{\sum \mathrm{X}}{\mathrm{N}}=\frac{2410}{32}=75,313
$$

Jika dibandingkan dengan tolak ukur masuk dalam kategori tuntas.

Tabel 1.6

Pedoman Interpresentasi Hasil Belajar Siswa

\begin{tabular}{cc}
\hline Standar Ketuntasan Minimal (SKM) & Kategori \\
\hline $70.00>$ & Tuntas \\
$<70.00$ & Tidak Tuntas \\
\hline
\end{tabular}

Sumber: Guru Mata Pelajaran PPKn Kelas VII

3. Untuk mencari pengaruh model pembelajaran cooperative berkirim salam dan soal terhadap hasil belajar

a. Mencari D (difference $=$ perbedaan) antara variabel $\mathrm{X}$ dan Variabel $\mathrm{Y} \mathrm{D}=\mathrm{X}-\mathrm{Y}$

$$
\begin{aligned}
& D=1950-2410 \\
& D=-460
\end{aligned}
$$

b. Mencari mean dari difference dengan rumus:

$$
\begin{aligned}
& \mathrm{MD}=\frac{\sum \mathrm{D}}{\mathrm{N}} \\
& \mathrm{MD}=\frac{-420}{32}=-14,375
\end{aligned}
$$

c. Mencari deviasi standar dan difference (SDD) dengan rumus:

$$
\begin{aligned}
& S_{D}=\sqrt{\frac{\sum D^{2}}{N}-\left(\frac{\sum D}{N}\right)^{2}} \\
& =\sqrt{\frac{9600}{32}-(-14,375)^{2}} \\
& =\sqrt{300-206,640625} \\
& =\sqrt{93,359375}=9,662
\end{aligned}
$$

d. Mencari standar error dari mean of difference yaitu $\mathrm{SE}_{\mathrm{MD}}$ dengan menggunakan rumus:

$$
\begin{aligned}
& \mathrm{SE}_{\mathrm{MD}}=\frac{\mathrm{SD}_{\mathrm{D}}}{\sqrt{\mathrm{N}-1}} \\
& =\frac{9,662}{\sqrt{32-1}} \\
& =\frac{9,662}{\sqrt{31}} \\
& =\frac{9,662}{5,568}=1,716
\end{aligned}
$$


e. Mencari to dengan menggunakan rumus:

$$
\begin{aligned}
& \text { to }=\frac{\mathrm{MD}}{\mathrm{SE}_{\mathrm{MD}}} \\
& \text { to }=\frac{-14,375}{1,736}=8,285
\end{aligned}
$$

Untuk mengetahui berapa besar pengaruh atau (tinggi rendah) menggunakan rumus Effect Sizesebagai berikut:

$$
\begin{aligned}
E s & =\frac{X e-X c}{S c} \\
& =\frac{60,938-75,313}{9,662} \\
& =1.49
\end{aligned}
$$

Keterangan:

Es = Effect Size

$\mathrm{Xe} \quad=$ Rata-rata Pretest

$X c \quad=$ Rata-rata Posttest

Sc $\quad=$ Standar Deviasi Kelas

Kriteria besarnya Effect Size adalah sebagai berikut:

Es $<0,3$ tergolong rendah

$0,3 \leq E s \leq 0,7$ tergolong sedang

Es> 0,7 tergolong tinggi

Jika nilai hitung $\mathrm{T}$ lebih besar dari nilai tabel $\mathrm{T}$, Hipotesis Alternatif (Ha) diterima dan Hipotesis Nol (Ho) ditolak. Kesimpulannya terdapat pengaruh penerapan model pembelajaran cooperative berkirim salam dan soal terhadap hasil belajar pendidikan kewarganegaraan siswa kelas VII di Sekolah Menengah Pertama Negeri 20 Pontianak. Jika nilai hitung T lebih kecil dari nilai tabel T, Hipotesis Nol (Ho) diterima dan Hipotesis Alternatif (Ha) ditolak. Kesimpulannya tidak terdapat pengaruh penerapan model pembelajaran cooperative berkirim salam dan soal terhadap hasil belajar pendidikan kewarganegaraan siswa kelas VII di Sekolah Menengah Pertama Negeri 20 Pontianak.

Hasil hitung nilai $\mathrm{T}=8,25 \geq$ nilai tabel $\mathrm{T} 2,04$, berarti Hipotesis Alternatif diterima sedangkan Hipotesis Nol (Ho) ditolak. Kesimpulannya terdapat pengaruh penerapan model pembelajaran cooperative berkirim salam dan soal terhadap hasil belajar pendidikan kewarganegaraan siswa kelas VII di Sekolah Menengah Pertama Negeri 20 Pontianak. 


\section{SIMPULAN}

Berdasarkan hasil penelitian yang diperoleh melalui proses pengelolaan dan analisis data, maka dapat ditarik kesimpulan secara umum bahwa penerapan model pembelajaran cooperative berkirim salam dan soal terhadap hasil belajar pendidikan kewarganegaraan siswa kelas VII Sekolah Menengah Pertama Negerti 20 Pontianaktergolong sedang dengan spesifikasi masalah sebagai berikut:

1. Hasil belajar siswa pada mata pelajaran Pendidikan Kewarganegaraan sebelum dilaksanakannya model pembelajaran cooperative berkirim salam dan soal terhadap hasil belajar pendidikan kewarganegaraan siswa kelas VII di Sekolah Menengah Pertama Negerti 20 Pontianak, termasuk dalam kategori "tidak tuntas", karena rata-rata hasil beajar yang dilakukan oleh peneliti adalah 60,94 .

2. Hasil belajar siswa pada mata pelajaran Pendidikan Kewarganegaraan setelah dilaksanakannya model pembelajaran cooperative berkirim salam dan soal terhadap hasil belajar pendidikan kewarganegaraan siswa kelas VII di Sekolah Menengah Pertama Negerti 20 Pontianak.termasuk dalam kategori “Tuntas”, karena rata-rata hasil belajar yang dilakukan oleh peneliti adalah 75,31. Ini dapat dilihat dari adanya keinginan siswa untuk berhasl dalam belajar, serta adanya semangat dan kebutuhan untuk meningkatkan hasil belajar dengan sangat baik.

3. Terdapat pengaruh model pembelajaran cooperative berkirim salam dan soal terhadap hasil belajar pendidikan kewarganegaraan siswa kelas VII di Sekolah Menengah Pertama Negerti 20 Pontianak. Ini dilihat dari perhitungan berapa besar pengaruh atau (tinggi rendah) menggunakan Effect Size yang hasilnya yaitu Es $=1.49$ "tergolong tinggi" dengan Kriteria besarnya Effect Size adalah Es $<0,3$ tergolong rendah, 0,3 $\leq E s \leq 0,7$ tergolong sedang, Es> 0,7 tergolong tinggi.

\section{DAFTAR PUSTAKA}

Arikunto, S. (2010) Penelitian Tindakan. Yogyakarta: Aditya Media.

Sugianto, (2010) Model-model Pembelajaran Inovatif. Surakarta: Yuma Pustaka. , (2010) Metode Penelitian Pendidikan. Bandung: Alfabeta.

Suryabrata, S (2000). Metodelogi Penelitian. Jakarta: Raja Grafindo Persada.

Trianto, (2007). Metode Pembelajaran Inovatif Berorientasi Konstruktivistik, Konsep, Landasan Teoritis-Praktis dan Implementasinya. Jakarta: Pretasi Pustaka.

Undang-Undang Sistem Pendidikan Nasional No. 20 Tahun 2003.

Zuldafrial, (2004). Bahan Ajar Mata Kuliah Penelitian Kuantitatif, Pontianak: STKIP-PGRI , (2012) Evaluasi Pendidikan \& Penelitian Tindakan Kelas. Pontianak: STAIN Pontianak Press.

, (2012). Penelitian Kuantitatif. Pontianak: STAIN. 